\title{
Research on the Development Strategy of the Belt and Road Construction and the New Urbanization-Take Yunnan as an Example
}

\author{
Yusheng $\mathrm{Gu}$ \\ International Business School \\ Yunnan University of Finance and \\ Economics \\ Kunming, China \\ 1004471883@qq.com
}

\author{
Honglie Zhang* \\ Dept. of International Exchange and \\ Cooperation \\ Yunnan University of Finance and \\ Economics \\ Kunming, China \\ 378493109@qq.com
}

\author{
Ruiting Wang \\ International Business School \\ Yunnan University of Finance and \\ Economics \\ Kunming, China \\ 281302812@qq.com
}

\begin{abstract}
At present, China has entered a new period of development. The"One Belt and One Road" initiative and the new urbanization strategy have entered a stage of comprehensive promotion, which will have an extremely important impact on China's regional development during the"13th Five-Year Plan" and beyond. In this context, the"One Belt and One Road"and the new urbanization are new initiatives and new strategies for the transformation and upgrading of the international and domestic perspectives. How to form interaction and integration between the two is an important issue to be considered.The" One Belt and One Road"and the new urbanization strategy are two important measures to promote China's future economic development. The two strategies are intertwined, mutually integrated and highly consistent. They cannot be separated from each other and must fully grasp their internal relations. Handle interactions, mutual promotion and complementary relationships. This paper takes Yunnan as the research object, and analyzes the possible impact of "One Belt and One Road"on new urbanization; the important supporting role of new urbanization on "One Belt and One Road"; and the development of "One Belt and One Road"and new urbanization. The strategic path illustrates the importance, mutual relations, and coordination of the two major strategies, with a view to promoting the coordinated development of the two strategies.
\end{abstract}

Keywords: "One Belt and One Road", new urbanization, regional coordination, linkage development

\section{INTRODUCTION}

In the 2015 Government Work Report, Premier Li Keqiang pointed out that the "One Belt and One Road" construction will be combined with regional development and opening up. China is currently in the stage of accelerating urbanization development, and its development potential is huge. The "One Belt and One Road" initiative will greatly optimize the development space and promote a new pattern of regional economic development.In 2013 and 2014,China has successively promulgated the strategic layout of "National New Urbanization Planning: 2014 2020" and the "One Belt and One Road" initiative, which has important strategic significance for China's economic transformation, urbanization development and regional economic integration. The new urbanization strategy is based on the economic development of the domestic region. The "One Belt and One Road" initiative tends to restructure the foreign economic and trade pattern. The starting point is different. However, there are still many coupling points between the two at a certain level. Interacting, interrelated, inseparable[1].

Since the introduction of the "One Belt and One Road" and the new urbanization, the academic community has acted swiftly, and relevant units have established numerous "One Belt and One Road" research institutes or new urbanization research institutes. Liu Weidong and other in-depth analysis of the scientific connotation and scientific issues of the "One Belt and One Road Initiative" and the impact on the spatial pattern of China's land development[2]. Du Debin and others proposed that the "One Belt and One Road" is a geo-initiative for the rejuvenation of the Chinese nation, and analyzes the risks and geostrategic contours that may be encountered during construction [3]. Zhu $\mathrm{Xi}$ and other organizations organized a talk on the "One Belt and One Road" initiative from the perspective of geography, analyzed the geopolitical significance, explored the differences among countries in the ASEAN region, and analyzed the revelation of geocooperation, etc., summarizing the current international community's co-construction. The four main inter-subjects of the "One Belt and One Road Initiative" [4].Under the new situation of the country's proposal to build the "One Belt and One Road" initiative,Yunnan should give full play to its geographical location, policy mechanism, traditional friendship and economic and trade advantages, strengthen exchanges and cooperation with South Asia, Southeast Asia and neighboring countries, and actively in the country. Play an important role in promoting the "One Belt and One Road" strategy [5]. Liu Peilin launched a new type of urbanization and the study of the theory and practice of retaining nostalgia [6] , Lu Dadao and other well-known young and middle-aged experts organized academic debates on the "Hu Huanyong Line" [7]. Chen

*Corresponding author 
Mingxing and others focus on the in-depth discussion and analysis of the "Hu Huanyong Line"[8], Chen Wen and other new urbanization research and judgment in key areas such as the Yangtze River Delta[9]. New urbanization is the engine of the new normal to pull down economic growth. With the implementation of the national "One Belt and One Road" and new urbanization planning strategies, the overall environment of the western region has undergone tremendous changes. The state has demanded higher requirements for Yunnan, where the geographical location has obvious advantages. The Yunnan region has to undertake the entire South Asia. As well as the strategic tasks of Southeast Asian countries opening up to the outside world.However, so far, it has been found that there is less research on the direct integration of the "One Belt and One Road" and the new urbanization development. Focusing on this issue, this paper sorts out the background of the "One Belt and One Road" and new urbanization, analyzes the possible impact of the "One Belt and One Road" strategy on Yunnan's new urbanization and the positive role of Yunnan's new urbanization construction on the "One Belt and One Road". How to promote the scientific path of the integration of the "One Belt and One Road" and the new urbanization of Yunnan.

\section{YUNNAN'S OPPORTUNITIES IN TWO MAJOR STRATEGIC BACKGROUNDS}

Since the 1990s, economic globalization has developed rapidly, and the spatial integration of economic and social development has surpassed the national scale, accelerating the flow and allocation of commodities, capital, personnel, political culture and other factors on a global scale. These factors and forces of globalization are having a profound impact on the socio-economic development and spatial processes of different regions. Economic globalization has changed the spatial relationship of the world, expanded transportation and communication networks, trade liberalization, financial restructuring, and new Regional trade agreements and other re-formed the flow of world goods, investment, labor and political rights[10].As globalization continues to advance, economic ties and interests ties between countries are closer.

Since the reform and opening up, with China's economic and social development and scientific and technological strength constantly improving, China's position in the world has also undergone earth-shaking changes. As the world's second largest economy, the world's largest trading nation, and the world's largest foreign exchange reserve country, China needs to establish a new global outlook [11]. At the same time, China's urbanization rate has rapidly increased from $17.9 \%$ in 1978 to $57.35 \%$ in 2016, and the urban population has jumped from 170 million to 790 million. The urbanization process has effectively promoted China's economic and social development and improved people's living and living conditions. However, it should be noted that the urbanization model of large-scale and rapid development in the past has been focused on quantitative growth, with emphasis on the growth of urban population, while neglecting urbanization and facing severe semiurbanization challenges; In the past, the urbanization development model also paid a huge resource and environmental cost. With the release of new urbanization,
China's urbanization process has entered a new stage of peopleoriented and transformational development.In addition, China's economic and social development is also at a critical stage of climbing the slopes. There are prominent contradictions and problems such as low industrial structure and overcapacity. It is necessary to actively adapt, grasp and lead the new normal of economic development.

Yunnan has played an important role in the inland gateway for a long time in China's foreign history. As early as the Qin and Han Dynasties, the "Southern Silk Road" created Yunnan, an open and prosperous ancient history. Yunnan North connects the Silk Road Economic Belt, and the South connects the Maritime Silk Road. It is the only province in China that can communicate with Southeast Asia and South Asia from the same time, and connects Europe and Africa through the Middle East. Yunnan is the geographical center of Asia. It is the intersection of the international and southern passages of the North-South Trans-Asian Railway and the East-East AsiaEuropean continent, and the new Eurasian Continental Bridge that connects the three oceans. The unique location advantage highlights Yunnan's position in the "One Belt and One Road" construction. As an important gateway for the organic integration of "One Belt and One Road", Yunnan has the advantages of location, platform carrier and convenient transportation. The "One Belt and One Road" strategy has profoundly changed the development pattern of urbanization in Yunnan and has given many new opportunities by promoting multi-domain interconnection,industrial agglomeration, orderly flow of resource elements and high market integration. Based on the "One Belt and One Road" framework, the development of new urbanization in Yunnan should establish the overall situation and cooperation concept of the development of the whole region, build a free flow channel for resource elements, strengthen the industry's driving and supporting functions, improve the county town system and interact with the development of large and medium-sized cities[12].

\section{THE POSSIBLE INFLUENCE OF THE “ONE BELT AND ONE ROAD” STRATEGY ON THE NEW URBANIZATION CONSTRUCTION IN YUNNAN}

\section{A. Accelerate the urbanization process in Yunnan}

Since the reform and opening up, Yunnan has been dominated by resource-intensive industries due to the comprehensive influence of geographical location, ecological environment and natural conditions. In order to improve the level of opening up in the southwest region, the State Council has successively approved the implementation plans for the development of key development and open pilot zones in Guangxi Dongxing, Yunnan Ruili, Yunnan Mengla (Menglu), etc. It is proposed that after 10 years of efforts, institutional and institutional innovation, foreign economic and trade cooperation. And infrastructure construction and other aspects have achieved results. The "One Belt and One Road" construction means that high-level "introduction" and largescale "going out" will be promoted simultaneously. The geographical value of the "One Belt and One Road" construction along the border areas is highlighted. The 
construction of "One Belt and One Road" will promote more participation in the international division of labor in Yunnan. Port cities and border areas will gain development opportunities and levels in infrastructure, trade logistics, international cooperation parks, cross-border e-commerce, and customs clearance. The implementation of "One Belt and One Road" has opened up the gateway of Yunnan Province and can give full play to the geographical advantages of Yunnan Province, making Yunnan Province an open window for China to open to South and Southeast Asian countries, which will inevitably cause foreigners. The influx of funds has enabled Yunnan's economy to develop rapidly, and the increase in economic development will also lead to the rapid development of new urbanization in Yunnan Province. Therefore, the construction of "One Belt and One Road" will further accelerate urbanization in Yunnan and promote the connection with new urbanization planning.

\section{B. Improve the location advantage of new urbanization in Yunnan}

The "One Belt and One Road" strategy requires the cooperation of central cities, node towns and surrounding areas along the line, and through the orderly cooperation and development between these regions and the countries along the line, further deepen the "One Belt and One Road" strategy and promote new urbanization. In the construction of the "One Belt and One Road", the responsibility and location of some cities and towns in Yunnan, especially the

"One Belt and One Road" node towns, will have an important positive effect on China's regional economic development. The "One Belt and One Road" strategy has further strengthened the construction and investment of infrastructure in urban areas. Through the interconnection of infrastructure construction, it has opened up economic channels between cities and regions along the urban areas, and further enhanced the "One Belt and One Road" strategy for urban areas. The economic role of China will enhance the location advantages of cities and towns, create new economic growth zones, and promote new urbanization. Especially in the Yunnan region, the traffic location conditions and infrastructure construction level are still relatively weak. The

"One Belt and One Road" strategy will promote the formation of new regional node towns, which will form a multi-node central town development pattern, in the "One Belt and One Road" strategy. The economic ties between the cities and regions along the cities and towns will be strengthened, and the urban location advantages will become more and more obvious. The urban areas will further promote the wider and more spacious and deeper areas of Yunnan's countries along the route under the guidance of the "One Belt and One Road" strategy. The level of opening up to the outside world[13].

\section{Improve the county town system and promote the coordinated development of urbanization in Yunnan}

Promoting the urban agglomeration with big cities as the core, the simultaneous development of county-level urban systems with county-level medium-sized cities, small cities, characteristic county towns and economically strong towns is the strategic orientation and goal of Yunnan's urbanization development. On the one hand, under the framework of "One Belt and One Road" , the construction of resource elements circulation channels and the improvement of the mechanism system will form a new pattern of clustering of all regions, multi-fields and wide-ranging factors; on the other hand, Yunnan will participate in the "One Belt and One Road" construction, the improvement of overall competitiveness and the timely follow-up of various regions are the key, thus determining the construction of strategic pivots, the radiation of central cities and the cultivation and creation of small and medium-sized cities are indispensable aspects, forming a central city, Large cities drive small and medium-sized cities and towns, and small and medium-sized cities and towns interact with central cities and large cities, and it is imperative to achieve mutual synergy.Firstly, national culture and ecological environment protection are equally important to create characteristic towns. Based on the advantages of abundant natural resources, distinctive national characteristics, diverse cultural customs and good ecological environment in Yunnan, the industrial development is highly integrated with national customs, culture and ecological environment, and the development of small towns and central cities are promoted by industrial development and economic cooperation. The development of the city has created a number of characteristic small towns with unique geographical advantages, rich ethnic connotations and natural beauty. Secondly, pay attention to border security issues in the development of border towns. The development of towns in the border areas has the consideration of border security. The development of urbanization is based on the convergence of residents to the central towns and the security of border territories. The residents need to be moderately dispersed in the borders. By strengthening the agriculture, forestry, processing trade and animal husbandry in the border areas. Such as the development of the industry, or open border ports to develop border trade in places where conditions permit, improve the inclusiveness and balance of the results of urbanization construction, and guide and encourage the establishment of entrepreneurship in the border areas[14].

\section{THE SUPPORTING ROLE OF YUNNAN'S NEW URBANIZATION CONSTRUCTION PROCESS ON THE "ONE BELT AND ONE ROAD"}

\section{A. Improve the level of people's livelihood in cities and towns improve the influence of the "One Belt and One Road" in countries along the southwest}

The improvement of the people's livelihood level in the to

wn contributes to the development speed of urbanization and provides better services for the promotion of the "One Belt and One Road" strategy. As one of the important strategic objectives of the "One Belt and One Road" , the people's heart is the key to realizing other strategic objectives such as "One Belt and One Road" infrastructure connectivity and policy communication. Through the commonwealth of the people, the countries and regions along the line can reach consensus in economic cooperation and political cooperation. In turn, we will concentrate on building a "One Belt and One 
Road" economic belt to achieve economic globalization and regional economic integration. The improvement of the people's livelihood in the town can be applied to the development of new urban industries in Yunnan, enterprise innovation, economic transformation, etc., to create a new type of town that is healthy, green, efficient and livable. It will attract more foreign high-quality labor and capital in the construction of the "One Belt and One Road". The transfer of technology and industrial production capacity will form a ties between countries and regions along the "One Belt and One Road" to increase their influence in countries along the "One Belt and One Road" [15]. It is easy to carry out the docking work of relevant organizations and provide the main carrier and platform for the implementation of "One Belt and One Road" .

B. Urban life transformation and upgrading to provide comprehensive service platform for "One Belt and One Road"

Urbanization is the only way for modernization. All countries in the world have experienced and are experiencing rapid development or are about to enter the mid-term urbanization development process. Yunnan's new urbanization is committed to realizing urbanization, adhering to the concepts of innovation, coordination, greenness, openness, and tolerance. It pays attention to the equalization of basic public services in urban and rural areas, pays attention to environmental livability and historical heritage, and pays attention to enhancing the happiness of the people. The transformation and upgrading of urban life has further improved the development and level of urban development, and helped to promote the socio-economic transformation of underdeveloped cities and rural areas along the southwestern region, providing industrial support and financial support for these areas, and further promoting the industrialization of such areas. Urbanization construction will improve its ability to participate in regional competition in the "One Belt and One Road" strategy, and achieve enterprise cooperation, capacity cooperation, and project cooperation among countries along the line, and provide an integrated service platform for the “One Belt and One Road” construction.

\section{Yunnan's urban characteristic culture drives the economic development of the "One Belt and One Road"}

Cultural cooperation and exchanges are important influencing factors for Yunnan to strengthen cooperation and exchanges with the "One Belt and One Road" countries along the southwest. Promote exchanges and cooperation between economic and technological talents under the influence of cultural exchanges, and further deepen the relationship between Yunnan and other countries along the line. Comprehensive cooperation [16]. Yunnan's characteristic urbanization has rich and diverse historical and cultural resources. It leads the cultural rejuvenation of the "One Belt and One Road" with the construction of humanities and towns, and can further strengthen and drive the economic revitalization of the "One Belt and One Road" . With culture as the link and cooperation and exchanges in the fields of economy and trade, we can further promote and realize the economic development of Yunnan.

\section{THE STRATEGIC PATH OF LINKAGE DEVELOPMENT BETWEEN “ONE BELT AND ONE ROAD” AND YUNNAN NEW URBANIZATION CONSTRUCTION}

\section{A. Constructing the overall situation and cooperation concept based on the "One Belt and One Road" and the development of new urbanization in Yunnan}

The "One Belt and One Road" is a global strategic layout that seeks overall development, overall development, linkage development and sustainable development. In the past, the traditional economic development mode was a conceptual development. The localized development thinking was deeply rooted. Without a pillar industry, there would be no GDP. Without GDP, there would be no political achievements. In the future, the decisive factor affecting the development potential, space and tension of urbanization in Yunnan is not whether it is at the starting point of the "One Belt and One Road", but whether it establishes a development concept and guarantee mechanism that adapts to the essence of the "One Belt and One Road" strategic concept. Whether to take advantage of the opportunities brought by the "One Belt and One Road" to establish unique industrial advantages, technological advantages, and innovation advantages. The development of new urbanization in Yunnan should proceed from the perspective of overall development, actively strengthen multifield cooperation between various regions in the region, between the region and surrounding provinces, between the region and neighboring countries, and build a new economic market and cooperation mechanism. Promote the free flow of resource elements, cross-regional and cross-border flows, strengthen the cultivation and development of local characteristic industries, base on the advantages of resource endowment, take industrial development as a link, take market expansion as a thrust, rely on the development platform to build, and cooperate Win-win and interactive development are the way to improve the level of urbanization in Yunnan.

\section{B. Open up the free flow channel of resource elements and reconstruct the new pattern of urbanization development in Yunnan}

The biggest feature of the "One Belt and One Road" strategy lies in interoperability and win-win cooperation. This is the philosophy that should be upheld in the development of urbanization. It is necessary to establish a sound transportation network system and ensure the free flow of resource elements in the physical sense. On this basis, the "One Belt and One Road" interconnection also means the integration of various institutional mechanisms that guarantee the ability of resource elements to flow freely. The new urbanization construction in Yunnan should take the "One Belt and One Road" as an opportunity to adhere to the equal emphasis on the transportation infrastructure and mechanism, and enhance the cooperation and linkage of urbanization development. In terms 
of infrastructure, we will promote infrastructure such as railways, highways, and ports in an orderly and planned manner based on the established transportation system, the

"One Belt and One Road" trend, and the development priorities and directions. In terms of interoperability of mechanisms and systems, the key point is to establish a fair and urban-rural integration mechanism for social resource allocation and sharing, to ensure the fairness and balance of education, housing and medical care for urban and rural residents, to promote urban-rural integration, and to establish information services and Sharing platforms to promote information sharing and cooperation among regions, industries, industries and enterprises.

\section{CONCLUSION}

The implementation and deepening of the "One Belt and One Road Initiative" will play an important role in the construction and development of new urbanization in Yunnan. Through the "One Belt and One Road" initiative, the urbanization process in Yunnan will be promoted, urbanization along the border areas will be promoted, and new towns in Yunnan will be promoted. Balanced development. It has promoted multi-level and inter-regional cooperation and exchanges in the fields of infrastructure, science and technology, talents, and industrial economy between Yunnan and other countries along the line, providing more funds and technology for the development of new urbanization in China., talent and other resources support. At the same time, the promotion of the new urbanization process in Yunnan will play an important supporting role in the implementation of the

"One Belt and One Road" initiative, improve the level of interconnection and intercommunication between countries along the line, and promote economic and trade ties and capacity cooperation among countries along the line through international cooperation in new urbanization. Friendly cities and international tourism are important links between the humanities and the people of the country along the line.

\section{ACKNOWLEDGMENT}

The authors thank other members of the research group for helpful, valuable, and constructive comments and suggestions on earlier versions of this paper. The paper is supported by the National Natural Science Foundation of China (No.71763028).

\section{REFERENCES}

[1] Wang Zhiyuan. International Background, Spatial Extension and Strategic Connotation of "Silk Road Economic Belt"[J]. Northeast Asia Forum, 2016(5).

[2] Liu Weidong. Scientific Connotation and Scientific Issues of the "One Belt, One Road" Strategy[J]. Advances in Geography, 2015, 34(5): 538544.

[3] Du Debin, Ma Yahua. "One Belt, One Road": The Geostrategy of the Chinese National Rejuvenation[J]. Geographic Research, 2015, 34(6): 1005-1014.

[4] Zhu Xi, Anning, Ge Hanwen, et al. Strategic Discussion on the "Belt and Road" Strategy Based on Geographical Perspectives[J]. , 2015, 35(5): 607-620.

[5] Cai Yifang. Research on Yunnan International Talent Development under the Background of "Belt and Road"[J]. Talent Resources Development, 2017(7):13-15.

[6] Liu Pei-lin. Theoretical and Practical Exploration of "Retaining Homesickness" in New Urbanization Construction[J]. Geographic Research, 2015, 34(7): 1205-1212.

[7] Lu Dadao, Wang Wei, Feng Zhiming, et al. Academic Controversy on "Can Hu Huanyong Line Break Through"[J]. Geographic Research, 2016, 35(5): 805-824.

[8] Chen Mingxing, Li Yang, Gong Yinghua, et al. Population Distribution and Urbanization Trends on Both Sides of Hu Huanyong LineTrying to Answer the Question of Premier Li Keqiang[J]. Acta Geographica Sinica, 2016, 71(2): 179-193.

[9] Chen Wen, Yan Dongsheng, Sun Wei, et al. Problems in the development of new urbanization in the Yangtze River Delta and the judgment of the situation[J]. Geographic Research, 2015, 34(3): 397-406.

[10] Liu Weidong, Zhang Guoqin, Song Zhouxi. Research on the Evolution Trend of China's Economic Development Spatial Pattern under the Background of Economic Globalization[J]. Geographic Science, 2007, 27(5): 609-616.

[11] Lu Dadao. Scientifically understand the "One Belt and One Road" [J]. Science and Technology Herald, 2018, 36(3): 1-1.

[12] Wu Qiong. Reflections on Yunnan's Participation in the Construction of the Greater Mekong Sub-region (GMS) Economic Corridor under the "One Belt, One Road" Strategy[J]. Economic Research Guide, 2016(3): 192-193.

[13] Feng Wu, Song Jiabao. Based on the advantages of Yunnan location implement the "going out" resource development strategy [J]. Commodity and Quality: Architecture and Development, 2012: 52-54.

[14] Zhang Shaowen, Guo Kaifeng, Zhu Debao, et al. Adaptability Exploration of Urban System Planning in Yunnan Province[J]. Programmer, 2012, 28(11): 35-39.

[15] Qiu Baoxing. Several Countermeasures for Realizing China's Harmonious Urbanization[J]. Journal of Nanjing University of Finance and Economics, 2006, 2006(1): 1-11.

[16] Fan Yan. Development of Yunnan's historical and cultural resources and urban cultural construction [D]. Yunnan University, 2012. 